Jurnal Santiaji Pendidikan, 2011, 1(2):121-130

ISSN 2087-9016

\title{
UPAYA MENINGKATKAN APRESIASI SASTRA MURID KELAS V SD NEGERI 4 SESETAN DENPASAR PADA BACAAN CERITA MELALUI LOKAKARYA MEMBACA
}

\author{
I Ketut Adnyana Putra \\ Universitas Pendidikan Ganesha Singaraja
}

\begin{abstract}
\end{abstract}
This class action research's objective is to develop the students literature appreciation year 5, to the story reading through reading workshop which focus on the developing of emotive response to the content of the story and the developing response at the character and event in the story. This research took place at SD 4 Sesetan Denpasar in two cyclus, in every cycle hare are two meeting. This subject research is year 5 teacher. The research data is collected using observation, interview, and document analyzing technique. The data is analyzed qualitatively which refers to ongoing analysis principle. The result of the research Indicates that through reading workshop activity, rind the procedure (1) mini lessons, that is introduction of the story book, selection of the story books based on the student's interest, (2) continued to the silent residing, (3) making dialogue journal, and at last (4) sharing, literature appreciation students year 5 elementary school to the story reading covers emotive response to the story contents, and the response to the character and event at the story develop.

Key words: Literature appreciation, story reading, and reading workshop

\section{PENDAHULUAN}

Pembelajaran sastra, khususnya menyangkut apresiasi sastra dipermasalahkan pengamat pendidikan dan sastrawan karena dirasakan tidak memenuhi harapan (Suharianto, dalam Dadan, 1998). Keluhan dan kekurangan pembelajaran sastra tersebut karena pembelajaran sastra hanya berkisar pada sejarah dan teori sastra, bukan pada apresiasi karya sastra. Para murid kurang diajak mengakrabi dan mengapresiasi karya sastra, padahal sesuai dengan pengertian karya sastra, adalah kegiatan menggauli cipta sastra dengan sungguh-sungguh hingga tumbuh pengertian, penghargaan, kepekaan kritis, dan kepekaan perasaan yang baik terhadap karya sastra.

Di sekolah dasar, pembelaiaran sastra dimaksudkan untuk meningkatkan kemampuan murid mengapresiasi karya sastra. Kegiatan 
mengapresiasi sastra berkaitan dengan latihan mempertajam perasaan, penalaran, daya khayal, serta kepekaan terhadap masyarakat, budaya dan lingkungan hidup (Depdikbud 1994:10). Hal tersebut diperkuat oleh pendapat Huck dkk. (1987) bahwa pembelajaran sastra di SD harus memberikan pengalaman pada murid yang akan berkonstribusi pada 4 (empat) tujuan, (1) pencarian kesenangan pada buku (discovering delight in books), (2) menginterpretasi bacaan sastra (interpreting literature), (3) mengembangkan kesadaran bersastra (literary awarness), dan (4) mengembangkan apresiasi (developing apreciation).

Untuk tercapainya apresiasi sastra seperti yang diinginkan/disarankan Rosenblatt (dalam Gani, 1988:13) beberapa prinsip sebagai berikut.

1) Murid harus diberikan kebebasan menampilkan respon dan reaksinya terhadap bacaan.

2) Murid harus diberikan kesempatan mempribadikan dan mengkristalisasikan rasa pribadinya terhadap cerita yang dibacanya.

3) Peranan guru harus merupakan daya dorong saat murid mengadakan eksplorasi.

Apresiasi murid pada bacaan cerita di SD (terteliti) selama ini masih kurang optimal. Kesan itu diperoleh dari hasil pengamatan di kelas V SD terteliti bahwa kegiatan apresiasi masih kurang optimal. Data penelitian pendahuluan ini memperlihatkan hasil sebagai berikut.

1) Guru belum mencoba memanfaatkan bacaan otentik. Teks yang digunakan hanya terpaku pada buku ajar, disajikan berupa penggalan yang ada pada buku ajar, tidak mencoba memanfaatkan bacaan secara utuh. Padahal SD terteliti memiliki buku cerita cukup banyak.

2) Saat pembelajaran apresiasi, kurang terlihat adanya pengoptimalan keterampilan berbahasa murid secara terpadu (membaca, menyimak, berbicara, dan menulis).

3) Murid kurang terlibat pada buku yang dibacanya. Hal ini ditandai dengan tidak terlibatnya emosi anak-anak pada kejadian cerita, tokoh cerita, dan isi cerita. Beberapa murid yang diwawancarai tentang sikapnya terhadap tokoh cerita dan emosinya terhadap kejadian cerita jawabannya tidak menampakkan hal yang emosional. Berbeda pada waktu ditanya tokoh cerita televisi mereka sangat antusias. 
Pembelajaran apresiasi sebagaimana dimaksudkan Kurikulum 1994 sangatlah perlu dilakukan. Dalam konteks persekolahan terutama pendidikan dasar, apresiasi merupakan salah satu wahana yang dapat mengembangkan dan membina emosi anak-anak. Salah satu alternatif cara yang dapat diupayakan dalam meningkatkan apresiasi murid pada bacaan cerita yaitu melalui Loka Karya Membaca (Reading Workshop).

Bertolak pada latar belakang tersebut, serta atas dasar pemikiran dan alasan-alasan itu, penelitian ini dilakukan.

\section{METODE}

\section{Rancangan Penelitian}

Adapun metode penelitian diorientasikan pada metode penelitian tindakan. Penggunaan metode penelitian tindakan dilakukan dengan mengidentifikasi gagasan umum yang dispesifikasikan sesuai dengan tema penelitian. Spesifikasi gagasan tersebut selanjutnya digarap melalui dua tahapan secara berdaur mulai dari perencanaan, pelaksanaan, pengamatan, dan refleksi (perenungan, pemikiran, dan evaluasi) (Kemmis dan McTaggart dalam Tomskins, 1993).

Penelitian ini dilakukan di SD Negeri 4 Sesetan Denpasar Selatan dengan subjek penelitian siswa kelas V yang berjumlah 29 orang. Pelaksanaan penelitian ini dilakukan selama empat minggu efektif.

\section{Rancangan Tindakan}

Rancangan tindakan pembelajaran Apresiasi Sastra pada bacaan cerita melalui lokakarya membaca didasarkan pada masalah penelitian meliputi: (a) prosedur lokakarya membaca yang bagaimanakah yang dapat meningkatkan tanggapan emotif siswa pada isi cerita, dan (b) prosedur loka karya membaca yang bagaimanakah yang dapat meningkatkan tanggapan pada pelaku dan peristiwa dalam cerita. Selanjutnya perencanaan pembelajaran tersebut dilakukan dalam dua siklus dengan dua kali pertemuan untuk setiap siklusnya. 


\section{Perencanaan Tindakan Siklus I}

Tujuan pembelajaran khusus pertemuan pertama lokakarya ini adalah agar siswa dapat mengungkapkan tanggapan emotif pada isi cerita, yang dapat dirinci menjadi :

1) Menyampaikan kesan tentang cerita yang telah dibacanya dalam bentuk jurnal dialog.

2) Memberikan alasan tentang kesan cerita yang telah dibacanya dalam bentuk jurnal dialog.

3) Mengungkapkan bagian cerita yang paling disukai/menarik dalam bentuk jurnal dialog.

4) Mengungkapkan alasan tentang bagian cerita paling disukai/menarik dalam bentuk jurnal dialog.

Kegiatan pembelajaran pertemuan kedua siklus I difokuskan pada tujuan pembelajaran agar siswa dapat mengungkapkan tanggapan tentang pelaku dan peristiwa dalam cerita, yang dirinci berikut ini.

1) Dapat menghubungkan peristiwa atau pelaku dalam cerita dengan pengalaman kehidupannya dalam bentuk jurnal dialog

2) Dapat mengemukakan pendapat tentang rasa simpatik pada pelaku yang paling disukainya dalam bentuk jurnal dialog.

3) Dapat memerankan pelaku pada suatu peristiwa yang ada dalam cerita.

\section{Perencanaan Tindakan Siklus II}

Perencanaan tindakan siklus II yang berbentuk satuan pelajaran tidak banyak mengalami perubahan dari perencanaan siklus I. Tujuan kelasnya tetap, yakni agar siswa mampu menyerap isi cerita serta dapat memberikan tanggapan. Demikian pula tujuan pembelajaran khususnya tetap mengacu pada dua fokus yaitu (1) agar siswa dapat memberikan tanggapan emotif pada isi cerita, dan (2) agar siswa dapat mengungkapkan tanggapan tentang pelaku dan peristiwa dalam cerita. Perubahan yang terjadi hanya pada kegiatan pembelajarannya, sebagai hasil dari refleksi siklus I.

Kegiatan belajar pertemuan kedua siklus II sebagai berikut: (1) guru bertanya jawab tentang pelaku dan peristiwa dalam cerita, (2) guru bersama murid membaca dalam hati, (3) siswa membuat jurnal dialog sesuai dengan tuntutan dalam tujuan pembelajaran, (4) siswa bersama dengan guru 
melakukan pertemuan kelompok, untuk selanjutnya mempersiapkan pemeranan, (5) siswa melakukan pemeranan tokoh cerita.

\section{Pelaksanaan Tindakan}

Siklus I dan Siklus II penelitian ini dilaksanakan dalam dua kali pertemuan. Proses tindakan pada pertemuan pertama siklus I dan II berupa kegiatan pembelajaran tanggapan emotif pada isi cerita, dilakukan dengan prosedur lokakarya yang telah ditetapkan pada tahap perencanaan. Demikian pula tindakan pertemuan kedua siklus I dan II yakni tanggapan siswa terhadap pelaku dan peristiwa dalam cerita juga dlakukan atas dasar perencanaan yang telah ditetapkan bersama oleh peneliti dan praktisi.

\section{Pengamatan dan Refleksi}

Kegiatan ini dilakukan secara kolaborasi antara peneliti dan praktisi. Pada kegiatan pengamatan bila yang melakukan pembelajaran adalah guru, maka peneliti bertindak sebagai pengamat demikian juga sebaliknya.

Kegiatan refleksi dilakukan setiap kegiatan pembelajaran berakhir. Pada kegiatan inilah temuan dan hasil pengamatan peneliti ditriangulasi dengan pendapat praktisi. Bila diperoleh hasil yang belum optimal, peneliti bersama praktisi mencari upaya untuk memaksimalkannya.

\section{Teknik Pengumpulan Data}

Ada empat teknik yang digunakan mengumpulkan data penelitian ini, yaitu (1) pengamatan, (2) wawancara, (3) catatan lapangan, dan (4) penggunaan dokumen.

\section{Data dan Sumher Data}

Data penelitian ini berupa (1) catatan tentang pelaksanaan atau prosedur loka karya yang terus diperbaiki sampai hasil dan prosesnya optimal, (2) deskripsi proses dan temuan selama lokakarya membaca, yaitu hasil observasi dan wawancara berupa kata verbal maupun nonverbal, (3) hasil selama lokakarya membaca yaitu jurnal dialog berupa kata verbal tulis.

Sumber data penelitian ini adalah siswa kelas V SDN. No. 4 Sesetan Denpasar berjumlah 29 orang. Berdasarkan pelaksanaan tindakan dari 29 siswa 
tercatat 25 siswa yang mengikuti tindakan secara rutin. Dengan demikian sumber data penelitian ini digunakan ke-25 siswa tersebut.

\section{Analisis Data}

Data yang telah terkumpul dalam penelitian ini dianalisis melalui kegiatan penyajian data dan penarikan kesimpulan. Proses analisa dilakukan dengan mengacu pada prinsip ongoing analysis. Sesuai dengan prinsip di atas, analisis data dilakukan sejak data awal terkumpul sampai pengumpulan data salesai dilakukan. Oleh karena itu setelah data pada siklus I terkumpul mulai tahap 1 dan 2, peneliti sudah melakukan analisis. Dan saat keseluruhan data terkumpul yakni mulai siklus I dan II maka diakukan pengkategorian dan pengkodean data untuk selanjutnya dimaknai.

\section{Triangulasi Data}

Triangulasi dilakukan dengan teknik triangulasi metodologis dengan mengacu pada penggunaan teknik wawancara, pengamatan, dan analiais hasil tulisan siswa. Terkait dengan temuan hasil, triangulasi dilakukan peneliti dalam hal ini dengan guru dan teman sejawat sehingga diperoleh penemuan hasil yang optimal.

\section{HASIL DAN PEMBAHASAN}

\section{Deskripsi Hasi1 Tindakan Lokakarya Membaca (LKM)}

Dari ke 29 siswa kelas V SD No. 4 Sesetan Denpasar yang dijadikan subjek penelitian ini, pada kenyataannya hanya 25 siswa yang benar-benar mengikuti tindakan pada siklus I dan siklus II. Oleh karena itu paparan hasil tindakan ini juga mengacu pada hasil kerja atau data dari ke 25 siswa tersebut.

\section{Kemampuan Memberikan Tanggapan Emotif pada Isi Cerita}

Target hasil yang harus dicapai apresiasi tanggapan emotif pada isi cerita adalah: (a) Siswa dapat menyampaikan kesan tentang cerita setelah membaca, (b) Siswa dapat memberikan alasan tentang perasaan yang dikemukakannya tersebut, (c) Siswa dapat mengungkapkan bagian cerita yang paling disukainya, dan (d) Siswa dapat memberikan alasan tentang bagian cerita yang paling disukainya tersebut. 
Kemampuan memberikan tanggapan secara emotif bila dirinci menggunakan rambu-rambu kemampuan apresiasi dapat disusun dalam tabel berikut ini.

Tabel Hasil Kemampuan Memberikan Tanggapan Emotif

\begin{tabular}{lrlrl}
\hline \multicolumn{1}{c}{ Kualifikasi } & & Siklus I & Siklus II \\
\hline Sangat baik & 16 & siswa & 22 & siswa \\
Baik & 7 & siswa & 3 & siswa \\
Cukup & 1 & siswa & - & \\
Kurang & 1 & siswa & - & \\
Sangat kurang & - & & - & \\
\hline
\end{tabular}

Memperhatikan tabel di atas tampak bahwa pada pelaksanaan tindakan siklus I, diperoleh hasil 16 orang siswa berkualifikasi sangat baik, 7 orang baik, 1 orang cukup, dan 1 orang lagi kurang.

Hasil tanggapan siswa secara emotif pada siklus II secara umum lebih baik dari siklus I. Siswa yang berkualifikasi sangat baik mencapai jumlah 22 siswa, sedangkan 3 siswa telah mencapai kualifikasi baik. Hal ini berarti dari 25 siswa yang dijadikan subjek penelitian ini, ke-25 siswa telah mampu memberikan tanggapan secara emotif terhadap bacaan cerita sesuai dengan isinya, dan telah mampu menunjukkan bagian cerita yang menarik serta yang kurang menarik, beserta alasan-alasannya yang terurai dengan sangat rapi, lugas, ekspresif.

\section{Kemampuan Memberikan Tanggapan pada Pelaku dan Peristiwa Cerita}

Berdasarkan pengamatan, hasil unjuk kerja siswa pada siklus I, dapat dikatakan bahwa secara umum siswa telah mampu memberikan tanggapan pada pelaku dan peristiwa dalam cerita dengan baik. Mereka telah mampu menuangkan pengalamannya yang mirip dengan cerita yang dibacanya. Kemampuan memberikan tanggapan pada pelaku dan peristiwa dalam cerita dapat dilihat dalam tabel di bawah ini. 
Jurnal Santiaji Pendidikan, 2011, 1(2):121-130

ISSN 2087-9016

Tabel Hasil Kemampuan Memberikan Tanggapan Pelaku dan Peristiwa dalam Cerita

\begin{tabular}{lrlrl}
\hline \multicolumn{1}{c}{ Kualifikasi } & \multicolumn{2}{c}{ Siklus I } & \multicolumn{2}{c}{ Siklus II } \\
\hline Sangat baik & 18 & siswa & 21 & siswa \\
Baik & 3 & siswa & 4 & siswa \\
Cukup & 3 & siswa & - & \\
Kurang & 1 & siswa & - & \\
\hline
\end{tabular}

Dari tabel di atas pada siklus I kegiatan LKM untuk tujuan meningkatkan kemampuan siswa memberikan tanggapan pada pelaku dan peristiwa dalam cerita rnenghasilkan 18 siswa berkualifikasi sangat baik, 3 siswa berkualifikasi baik, 3 siswa berkualifikasi cukup, dan 1 siswa berkualifikasi kurang.

Atas dasar hasil kerja siswa pada siklus I, peneilti bersama guru selaku praktisi berdiskusi untuk mencari alternatif lain sebagai upaya peningkatan pembelajaran apresiasi pada bacaan cerita. Dengan mengadakan beberapa perubahan kegiatan pembelajaran melalui lokakarya membaca tersebut, peneliti bersama praktisi kembali melakukan tindakan yaitu siklus II, yang akhirnya diperoleh hasil siswa yang berkualifikasi sangat baik meningkat menjadi 21 orang, dan 4 siswa lainnya berkualifikasi baik. Oleh karena adanya peningkatan hasil yang cukup berarti atas tindakan lokakarya membaca tersebut peneliti akhirnya mengambil kesimpulan untuk menghentikan tindakan.

\section{Pembahasan}

Lokakarya membaca yang diperkenalkan pertama kali oleh Nancie Atwell (1987) adalah suatu pendekatan whole language yang mengintegrasikan pengajaran mini, membaca dalam hati dan tanggapan tertulis terhadap bacaan dalam bentuk jurnal dialog.

Lokakarya membaca menyediakan waktu yang konsisten untuk membaca terutama membaca dalam hati, karena ada keyakinan bahwa anakanak belajar membaca harus bergaul langsung dengan bacaan bukan lewat teori. Kegiatan membaca otentik yang dilakukan dalam penelitian inipun didukung oleh pendapat Holdaway (1980) yang mengatakan bahwa kegiatan 
membaca yang menguntungkan para siswa adalah membaca dengan cara alamiah dan bahan otentik, bukan penggalan atau sinopsis cerita.

Belajar mengadakan pemilihan buku secara pribadi sesuai dengan minatnya atau siswa diberikan kesempatan seluas-luasnya untuk memilih sendiri bacaannya akan menumbuhkan perkembangan pengetahuan sastra dan meningkatkan kefasihan membaca serta kebiasaan membaca. Namun demikian perlu diketahui oleh para guru, bahwa upaya membaca individu bisa berhasil bila guru benar-benar sadar akan keadaan para muridnya sebagai pembaca. Kemampuan guru dalam mengamati murid-muridnya membaca dalam hati, akan memberikan asesmen yang akan bisa mendorong guru untuk mengambil keputusan yang tepat.

\section{SIMPULAN DAN SARAN}

\section{Simpulan}

Simpulan yang dapat ditarik dari hasil penelitian ini adalah:

1) Melalui kegiatan lokakarya membaca kemampuan murid membuat tanggapan isi cerita pada umumnya sangat baik.

2) Melalui kegiatan lokakarya membaca kemampuan murid membuat tanggapan pada pelaku dan peristiwa dalam cerita umumnya sangat baik. Dengan perkataan lain pembelajaran apresiasi sastra melalui kegiatan lokakarya membaca dapat membuat murid berinteraksi apresiatif pada bacaan cerita.

\section{Saran}

Berdasarkan simpulan di atas dapat diajukan saran sebagai berikut:

3) Agar murid tidak bosan karena pembelajaran membaca hanya bersumber dari buku paket, buku cerita yang ada di perpustakaan sekolah dapat dimanfaatkan guru lewat kegiatan lokakarya membaca.

4) Tuntutan apresiasi bukan hanya pada produk tetapi juga proses. Untuk itu guru sebaiknya tidak hanya mementingkan hasil, tetapi juga memantau proses apresiasi murid melalui jurnal dialog, atau dialog membaca. 
Jurnal Santiaji Pendidikan, 2011, 1(2):121-130

ISSN 2087-9016

\section{DAFTAR PUSTAKA}

Aminuddin. 1996. Pengajaran Melalui Penelitian Area Isi Teks Naratif. Malang: PPS IKIP Malang.

-------. 1997. Pemahaman dan Penikmatan Bacaan Sastra Bagi Anak Usia Sekolah Dasar. Malang : PPS IKIP Malang.

Atwell, Nancie. 1987. In the Middle : Writing, Reading, and Learning with Adolescents. United States: Cook Publisher Inc.

Beach, R. 1991. Teaching Literature in the Secondary School. San Diego : Harcourt Brace Inovovich.

Combs, Martha. 1996. Developing Competent Readers and Writers in the Premary Grade. Ohio: Merrill Prentice Hall.

Dadan, J. 1996. "Sastra Anak Sebagai Landas Tumpu Pembelajaran Lintas Kurikulum". Makalah disajikan dalam Seminar Program Studi PGSD. Malang: PPS.

Depdikbud. 1994. Kurikulum Pendidikan Dasar; Landasan Program dan Pengembangan. Jakarta : Depdikbud.

Gani, Rizanur. 1988. Respon dan Analisis. Padang : Dian Dinamika Press.

Holdaway, Don. 1980. Independence in Reading. Sydney : Ashton Scholastic.

Hopkins, 1933. A Teacher's Guide To Classroom. Philadelphia : Open University Press.

Syafi'ie, Imam. 1995. "Pendekatan Whole Language dalam Pembelajaran Bahasa. Dalam Bahasa dan Seni. Tahun 23. No. 2 Agustus 1995.

Sutherland, Z. dan M-N. Arbuthnot. 1991. Children and Books. New York : Harper Collins Publhiser.

Wasena. 1994. Wawasan dan Konsep Dasar Penelitian Tindakan Pendidikan. Makalah disampaikan dan dibahas pada Pelatihan Penelitian Tindakan yang Diselenggarakan di IKIP Yogyakarta, tanggal 9-12 Januari 1994.

Weseman, D.L. 1992. Learning to Read with Literature. US : Allyn and Bacon. 